\title{
Identification of novel molecules and pathogenic pathways in primary biliary cirrhosis: cDNA array analysis of intrahepatic differential gene expression
}

\author{
N A Shackel, P H McGuinness, C A Abbott, M D Gorrell, G W McCaughan
}

\begin{abstract}
Background-Primary biliary cirrhosis (PBC) is an autoimmune disease in which the pathogenesis of progressive liver injury is poorly understood.

Aim-To provide novel insights into the pathogenesis of $\mathrm{PBC}$ related liver injury using cDNA array analysis, which simultaneously examines expression of many genes.
\end{abstract}

Methods-Utilising cDNA arrays of 874 genes, PBC was compared with primary sclerosing cholangitis (PSC) associated cirrhosis and non-diseased liver. Differential expression of 10 genes was confirmed by real time quantitative reverse transcriptase-polymerase chain reaction (RT-PCR).

Results-Array analysis identified many differentially expressed genes that are important in inflammation, fibrosis, proliferation, signalling, apoptosis, and oxidative stress. PBC was associated with increased expression of both Th1 and Th2 type molecules of the immune response. Fibrosis related gene expression featured upregulation of connective tissue growth factor and transforming growth factor beta3. Many more apoptosis associated molecules exhibited increased expression, consistent with apoptosis being a more active and regulated process, in PSC associated cirrhosis than in PBC. Increased expression of many genes of the Wnt and notch pathways implicated these highly conserved and linked pathways in PBC pathogenesis. The observed increases in expression of c-jun, c-myc, and c-fos related antigen 1 are consistent with increased Wnt pathway activity in PBC. Differential expression of four components of the Wnt pathway, Wnt-5a, Wnt13, FRITZ, and beta-catenin, was confirmed by quantitative RT-PCR.

Conclusion-Many genes implicated in intrahepatic inflammation, fibrosis, and regeneration were upregulated in PBC cirrhosis. In particular, increased expression of a number of Drosophila homologues was seen in PBC.

(Gut 2001;49:565-576)

Keywords: primary sclerosing cholangitis; apoptosis; fibrosis; connective tissue growth factor; Wnt; Th1/Th2; brain derived neurotrophic factor; notch
The pathogenesis of primary biliary cirrhosis (PBC) involves immune mediated injury of bile ducts and is characterised by multiple autoantibodies to mitochondrial antigens (antimitochrondrial antibodies (AMA)). ${ }^{1-3}$ Investigation into the pathogenesis of PBC has focused principally on the mitochondrial antigens, ${ }^{3}$ AMA characterisation, ${ }^{2}$ and the nature of the immune infiltrate around bile ducts. ${ }^{1}$ Targeting of the biliary epithelium may be explained by abnormal expression of mitochondrial antigens on the luminal surface of biliary epithelial cells. ${ }^{4}$ The aberrant mitochondrial antigen expression is thought to result in a breakdown of tolerance leading to immune mediated liver injury. ${ }^{3}$ An alternative hypothesis that PBC results from an immune response initiated due to an infectious agent is under investigation. ${ }^{5}$

In PBC, damage to the biliary epithelium and progressive liver injury leading to cirrhosis appears to be mainly due to a cell mediated immune response. The mononuclear cell infiltrate in PBC is characterised by activated $\mathrm{CD}^{+}$and $\mathrm{CD}^{+} \mathrm{T}$ lymphocytes with a predominant Th1 response. ${ }^{6-9}$ However, we have observed intrahepatic upregulation of interleukin (IL)-2 but not interferon (IFN) $-\gamma$ in PBC, which suggests that PBC does not universally conform to the Th1 paradigm. ${ }^{10}$

Abbreviations used in this paper: ABI, Applied Biosystems Incorporated; AMA, antimitochrondrial antibodies; BDNF, brain derived neurotrophic factor; $\mathrm{CDK}$, cyclin dependant kinase; cDNA, complementary DNA; CTGF, connective tissue growth factor; CXCR, CXC chemokine receptor; dATP, 2' deoxy -adenosine 5' triphosphate; dCTP, 2' deoxy-cytidine 5 ' triphosphate; dGTP, 2' deoxy-guanosine 5' triphosphate; dNTP, deoxy-nucleotides; dTTP, 2' deoxy-thymidine 5' triphosphate; EMMPRIN, extracellular matrix metalloproteinase inducer; EGF, epidermal growth factor; FGF, fibroblast growth factor; FRITZ, secreted frizzled related protein 3; Fz, frizzled; GDNF, glial cell line derived neurotrophic factor; HGF, hepatocyte growth factor; HSC, hepatic stellate cell; HSP, heat shock protein; IAP, inhibitor of apoptosis protein; IFN, interferon; IGFBP, insulin-like growth factor binding protein; IL, interleukin; MCP, monocyte

chemoattractant protein; MMP, matrix

metalloproteinase; MRP-8, migration inhibitory factor related protein 8; NGF, nerve growth factor; NT, neurotrophin; PBC, primary biliary cirrhosis; PCR, polymerase chain reaction; PDGF, platelet derived growth factor; PSC, primary sclerosing cholangitis; PTC, patch homologue; RT, reverse transcriptase; SCL, stem cell protein; TAF, TATA box binding protein associated factor; TAL-1, stem cell protein; TGF, transforming growth factor. 
$\mathrm{T}$ cells of most patients recognise purified oxo-acid dehydrogenase mitochondrial multienzyme complex antigens ${ }^{11}$ but the role of autoantibodies to these antigens is controversial. ${ }^{2}{ }^{12}$ There is some evidence of "molecular mimicry"13 where a cross reactive antigen is targeted by an immune response initially induced by a micro-organism. ${ }^{14}$ The presence of a cross reactive antigen is possible given that the titre of $\mathrm{AMA}^{2}$ and the $\mathrm{T}$ cell response ${ }^{15}{ }^{16}$ to mitochondrial antigens do not always correlate with disease severity or even the presence of disease. Binding of AMA to purified biliary epithelial cells differs markedly for various antibodies suggesting that there are multiple epithelial antigens with epitope cross reactivity. ${ }^{17} 18$

The immune response in $\mathrm{PBC}$ results in progressive bile duct damage and tissue fibrosis. Many fibrotic mediators in PBC may arise from damage to biliary epithelium with release of fibrogenic growth factors such as epidermal growth factor (EGF), basic fibroblast growth factor (FGF), transforming growth factor (TGF) beta, and platelet derived growth factor (PDGF). ${ }^{19} 20$ These fibrotic mediators lead to activation of the hepatic stellate cell (HSC) with release of basic FGF, hepatocyte growth factor (HGF), and TGFbeta. Autocrine stimulation of the activated HSC with PDGF, basic FGF, and TGF-beta, and stimulation of the biliary epithelium with EGF and HGF help maintain the initiated fibrogenic stimulus. ${ }^{21} 22$ Inflammatory mediators such as monocyte chemotactic factor 1 (MCP-1) are thought to stimulate the fibrotic response in $\mathrm{PBC} .^{20}$

Analysis of differential gene expression is an important approach to understanding liver injury pathogenesis. Classical approaches have examined mRNA expression of individual candidate genes such as growth factors (for example, connective tissue growth factor $(\mathrm{CTGF})^{23}$ ), cytokines (for example, IL- $8^{10}$ ), and chemokines (for example, IP- $10^{24}$ ). Unfortunately, methods of detecting differential gene expression such as northern blot analysis and semiquantitative reverse transcriptasepolymerase chain reaction (RT-PCR) are laborious and have explored few genes. Pathogenic processes involved in liver injury, such as inflammation, proliferation, apoptosis, and fibrosis, are inter-related and increasing numbers of genes are being identified as important in each pathogenic process. Clearly, approaches that can simultaneously examine differential expression of many genes are likely to lead to significant advances in understanding pathogenic pathways involved in liver injury. Therefore, in this study we used complementary DNA (cDNA) array analysis to examine intrahepatic differential gene expression in PBC. This paper describes multiple novel observations of differentially expressed genes and pathways implicated in the above mentioned pathogenic processes. Interestingly, the Wnt pathway was strongly implicated in PBC pathobiology for the first time.

\section{Methods}

TISSUE AND RNA ISOLATION

Total RNA was isolated from end stage cirrhotic PBC $(n=6)$ and end stage cirrhotic primary sclerosing cholangitis (PSC) $(n=4)$ tissue obtained from liver explants. Non-diseased tissue was obtained from transplant donor liver biopsies $(n=4)$ and from normal liver (distant from the tumour margin) during hepatic metastasis resection $(n=4)$. Tissue was obtained following institutional ethics committee approval and Australian Medical Research Council guidelines. Chronic inflammatory activity and end stage cirrhosis were evident in all of the cirrhosis specimens. RNA extraction using guanidine isothiocyanate dissolution and isopropanol precipitation has been described previously. ${ }^{10}$ Poly $\mathrm{A}^{+} \mathrm{mRNA}$ for array probe synthesis was isolated from pools of four individual RNA samples using oligo- $\mathrm{dT}_{18}$ cellulose (Roche Molecular Systems Inc., Branchburg, New Jersey, USA) by standard methods. ${ }^{25}$ The pooling of samples is a means of normalising for individual differences in array analysis. ${ }^{26}$

CDNA ARRAY ANALYSIS

Two nylon membrane based cDNA arrays were used: (a) ATLAS Human Gene Array 1.0 (588 genes and nine housekeeping genes) and (b) ATLAS Cytokine/Receptor Array (268 genes and nine housekeeping genes) (Clontech Laboratories, Inc., Palo Alto, California, USA) (fig 1). A list of all of the genes on these two arrays with summaries of gene functions is at www.clontech.com/atlas.

Probes from cirrhotic PBC, cirrhotic PSC, donor liver, and normal liver tissues were hybridised to both an ATLAS Cytokine Array and an ATLAS Human Gene Array. Probe synthesis was performed as recommended by the manufacturer with some modifications. During first strand cDNA synthesis, $1-2 \mu \mathrm{g}$ of poly $\mathrm{A}^{+}$mRNA were labelled in a $20 \mu \mathrm{l}$ reaction with $7.5 \mu \mathrm{l}$ of $\alpha^{32} \mathrm{P}$-dCTP $(10 \mu \mathrm{Ci} / \mu \mathrm{l}, 3000$ $\mathrm{Ci} / \mathrm{mmol}$; NEN Life Science Products, Inc., Boston, Massachusetts, USA) with $1 \mu \mathrm{l}$ of Superscript II RT (Gibco-BRL Gaithersburg, Maryland, USA), $4 \mu \mathrm{l}$ of $5 \times$ reaction buffer, $2 \mu \mathrm{l}$ of $100 \mathrm{mM}$ dithiothreitol, $0.5 \mu \mathrm{l}$ of RNase inhibitor (Promega Corp., Madison, Wisconsin, USA), $1 \mu \mathrm{l}$ of gene specific primer mix (Clontech), water, and $2 \mu \mathrm{l}$ of deoxynucleotides (dNTPs) (5 $\mathrm{mM} \quad 2^{\prime}$ deoxyadenosine $5^{\prime}$ triphosphate (dATP), 2' deoxythymidine 5' triphosphate (dTTP), 2' deoxyguanosine 5' triphosphate (dGTP), and $50 \mu \mathrm{M}$ $2^{\prime}$ deoxy-cytidine $5^{\prime}$ triphosphate (dCTP); Amersham Pharmacia Biotech UK Ltd, Buckinghamshire, UK) at $48^{\circ} \mathrm{C}$ for 40 minutes. Unincorporated nucleotides were removed using resin based Chroma spin-200 columns as recommended by the manufacturer (Clontech). Probes at a final concentration of $2-4 \times 10^{6} \mathrm{CPM} / \mathrm{ml}$ were hybridised to each array membrane for approximately 15 hours in Express $\mathrm{Hyb}$ hybridisation solution at $68^{\circ} \mathrm{C}$ (Clontech). The array membranes were washed in decreasing concentrations of SSC. Signals from the array membrane were quantified using a GS-525 Molecular Imager and 
A

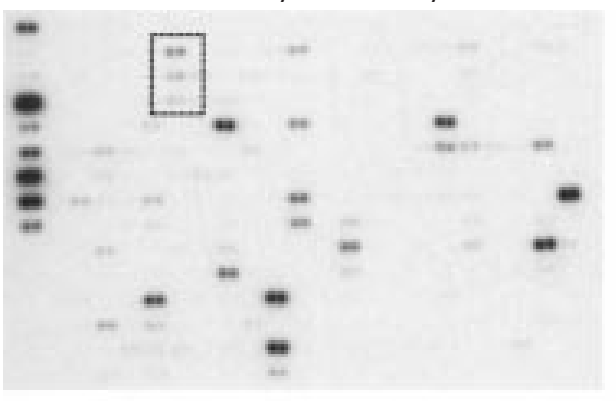

C

MCP-1 upregulation in PBC

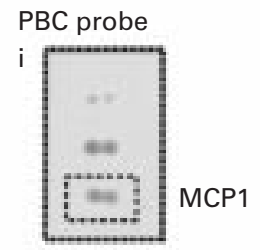

Normal probe

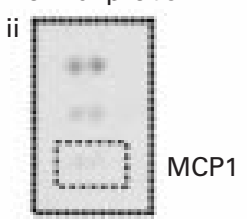

B ATLAS Human Gene Array 1.0

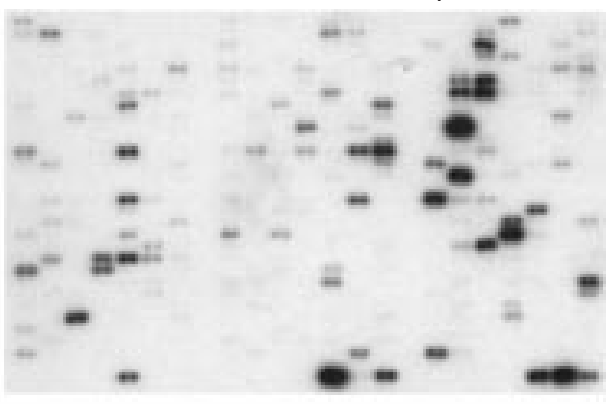

D

D Regression analysis

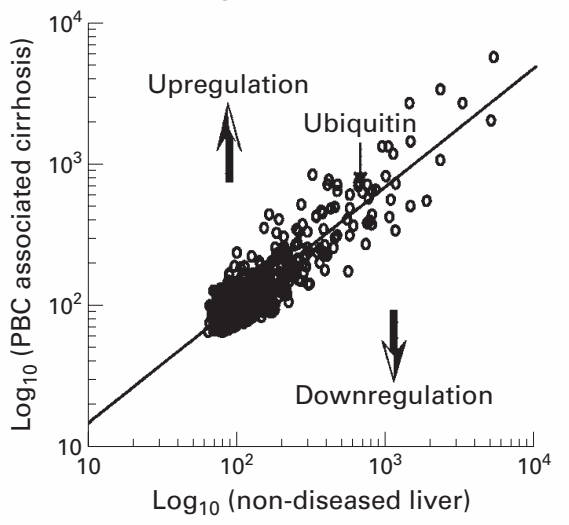

Figure 1 Examples of cDNA arrays. ATLAS Cytokine Receptor Array (268 genes and nine housekeeping genes) (A) and ATLAS Human Gene Array 1.0 (588 genes and nine housekeeping genes) (B), both probed with ${ }^{32} P-2^{\prime}$

deoxy-cytidine 5' triphosphate (dCTP) labelled primary biliary cirrhosis (PBC) $m R N A$ (pooled from four subjects). The magnified portion of the ATLAS Cytokine Receptor Array compares the ${ }^{32} P-d C T P$ signal from the PBC and normal liver probes. Upregulation of monocyte chemoattractant protein 1 (MCP-1) in PBC (in the small broken line boxes) is shown $(C)$. Regression analysis (D); this example compares signals generated using the $P B C$ probe with signals generated using a probe derived from non-diseased tissue (the normal liver probe) for each gene on the ATLAS Human Gene Array 1.0. The regression line equation was $P B C=2.0684 \times$ non-diseased ${ }^{0.83854}, r^{2}=0.76, p<0.0001$. The extent of differential expression for each gene was determined as a ratio of the raw array signal intensity to the signal intensity calculated from the regression line formula.

Molecular Analyst Software (Bio-Rad Laboratories Inc., Hercules, California, USA). Additionally, all arrays were exposed to film (MS Film with an MS Screen; Eastman Kodak Company, New Haven, Connecticut, USA). The signal from a blank portion of the cDNA array was taken as background. Individual gene expression on each array was adjusted for background.

SELECTION OF HOUSEKEEPER GENE

On the regression plots, such as that depicted in fig $1 \mathrm{D}$, ubiquitin did not exhibit significant differential expression and was selected as the housekeeper gene. Data on the other eight housekeeper genes were not used because phospholipase A2 and hypoxanthine-guanine phosphoribosyltransferase signals were less than twice the background, and brain specific tubulin alpha 1 subunit, cytoplasmic betaactin, MHC class I antigen C-4 alpha subunit, and glyceraldehyde 3-phosphate dehydrogenase were differentially expressed in cirrhosis.

\section{SENSITIVITY AND REPRODUCIBILITY OF CDNA}

ARRAYS

Over $95 \%$ of the cDNA spots on the array had detectable signals following hybridisation. Signal intensity on the arrays varied by four orders of magnitude. Low abundance signals were defined as signals less than twice background and represented at least $61 \%$ of the signals on the arrays. Given the use of ${ }^{32} \mathrm{P}$ labelled probes to maximise sensitivity, 90 signals were excluded from subsequent analysis due to blooming or membrane contamination. The raw housekeeping gene signals were greater from the cirrhotic liver probes than from the normal or donor liver probes, causing our experiments to preferentially detect up- rather than downregulation. Data were used only when at least one of the signals was $50 \%$ or more above background.

Pairwise comparative gene expression was determined from signal intensities with the four different probes (PBC cirrhosis, PSC cirrhosis, donor tissue, and normal tissue). Data are presented as a ratio generated by one of two methods:

(1) Signal intensities converted to a ratio adjusted for background and housekeeper gene (ubiquitin) expression:

((gene A probe A - background from probe A)/(housekeeper gene probe A - background from probe A) $) /($ gene A probe B - background from probe $\mathrm{B}$ )/(housekeeper gene probe $\mathrm{B}$ - background from probe B)).

(2) Regression analysis, a method that did not require adjustment for background or housekeeper gene signal (fig 1D). A non-linear power 
regression analysis on a logarithmic scale was used because the signal intensities varied by four orders of magnitude. Each observed signal was divided by each calculated signal, calculated from the regression line formula derived from all signals in each pairwise tissue comparison.

The reported ratio comparing expression of each gene used the method that generated the greater value. Individual genes that exhibited greater than 1.5-fold upregulation were categorised with the pathogenic processes of inflammation, fibrosis, proliferation, stress response/ oxidative stress, apoptosis, and intracellular signalling pathways. Genes were categorised by pathogenic process according to the array manufacturer's guidelines and known gene functions. Many genes could be included in multiple categories, so genes were grouped into pathogenic processes using this descending hierarchy: (i) intracellular signalling and nuclear, (ii) apoptosis, (iii) inflammation, (iv) proliferation, (v) fibrosis and (vi) stress response/oxidative stress associated genes, and (vii) uncategorised genes.

In addition, comparative expression data on individual genes were plotted graphically; genes were clustered according to the nature and extent of their differential expression over the three comparisons. Clustering used the Cluster and TreeView software (M Eisen, Stanford University). ${ }^{27}$ This hierarchical clustering method uses pairwise average linkage analysis and no a priori knowledge of gene function.

\section{QUANTITATIVE RT-PCR}

To confirm differential expression in individual patient specimens, mRNA of a selection of genes was quantified by real time RT-PCR using a modification of published methods. ${ }^{28}$ The genes assayed were: Wnt-5a, Wnt-13, CTGF, extracellular matrix metalloproteinase inducer (EMMPRIN), stromal cell derived factor 1 receptor (CXCR4), follistatin, secreted frizzled related protein 3 (FRITZ), beta-catenin, Jagged-1, and patch homologue (PTC).

Briefly, $5 \mu \mathrm{l}$ of total RNA $(5 \mu \mathrm{g})$ was primed with $3 \mu \mathrm{l}(500 \mathrm{ng})$ of oligo-d $\mathrm{T}_{18}$ primer (Roche Diagnostics, Indianapolis, Indiana, USA) and then reverse transcribed at $42^{\circ} \mathrm{C}$ for 50 minutes. The reaction mix $(20 \mu \mathrm{l})$ also contained $4 \mu \mathrm{l}$ of $5 \times$ reaction buffer, $2 \mu \mathrm{l}$ of $100 \mathrm{mM}$ dithiothreitol, $0.5 \mu \mathrm{l}$ of RNase inhibitor (Promega), $1 \mu \mathrm{l}$ of $10 \mathrm{mM}$ dNTPs (Amersham), $1 \mu$ l of Superscript II (Gibco-BRL), and $3.5 \mu \mathrm{l}$ of $\mathrm{H}_{2} \mathrm{O}$. After cDNA synthesis the total volume was made up to $80 \mu \mathrm{l}$ with $\mathrm{H}_{2} \mathrm{O}$. Two cDNA samples were prepared from each RNA sample and then stored at $-70^{\circ} \mathrm{C}$ until needed. Each real time PCR reaction contained $1 \mu \mathrm{l}$ of cDNA, $2.5 \mu \mathrm{l}$ of $10 \times$ TaqMan reaction buffer A (PE Biosystems, Foster City, California, USA), $4 \mu \mathrm{l}$ of $25 \mathrm{mM}$ $\mathrm{MgCl}_{2}, 0.5 \mu \mathrm{l}$ of $10 \mathrm{mM}$ dNTPs, $1 \mu \mathrm{l}$ of $5 \mathrm{mM}$ forward and reverse primer, $0.18 \mu \mathrm{l}(5.5 \mathrm{U} / \mathrm{l})$ of AmpliTaq Gold polymerase (PE Biosystems), $0.25 \mu \mathrm{l}$ of $50 \times$ Sybr Green 1 (Molecular Probes, Eugene, Oregon, USA), and $\mathrm{H}_{2} \mathrm{O}$ for a $25 \mu \mathrm{l}$ total volume. Cycling parameters were $95^{\circ} \mathrm{C}$ for 10 minutes followed by 40 cycles of $95^{\circ} \mathrm{C}$ for 30 seconds, 40 second ramp, $60^{\circ} \mathrm{C}$ for 30 seconds, 20 second ramp, $72^{\circ} \mathrm{C}$ for one minute, 17 second ramp, and 30 seconds for fluorescence measurement. This measurement resolved the gene of interest from non-specific products of amplification such as primer-dimers and was achieved using a measurement temperature that ranged from 82 to $86^{\circ} \mathrm{C}$ (determined by melting point analysis of each product). ${ }^{28}$ The reactions were performed in duplicate using an Applied Biosystems Incorporated (ABI) Model 7700 Sequence Detector (PE Biosystems) and analysed using ABI Prism Sequence Detector Software v1.6.3 (PE Biosystems). A gene specific DNA standard was included in each assay. Confirmation of a single PCR product was performed by gel analysis and the identity of the amplified PCR product was confirmed by sequencing (ABI 373 Sequencer using dye terminator chemistry; PE Biosystems). Ubiquitin, the housekeeper gene, was quantified in all cDNAs.

The primer sequences were: Wnt-5a forward 5' GCAATGTCTTCCAAGTTC 3', reverse 5' AAGTGGCACAGTTTCTTC 3'; Wnt-13 forward 5' GAGTGTCAGCACCAATTCC 3', reverse 5' CACCCCAGTCAAAAGTCC 3'; CTGF forward 5' TCCCACCCAATTCA AAAC 3', reverse 5' CAAAATAGCAGGCAT ATTACTCG3'; CXCR4 forward 5' TCAGT GAGGCAGATGACAG 3', reverse 5' TCCC AATGTAGTAAGGCAG 3'; EMMPRIN forward 5' ACAAGATCACTGACTCTG AGGAC 3', reverse 5' TTCTCAATGTG TAGCTCTGACC 3'; follistatin forward 5' CCTCAACCCATCTTTCAAC 3', reverse 5' CCCCTTCTGATTCTTTCC 3'; betacatenin forward 5' CATTACAACTCTCCA CAACC 3', reverse 5' CAGATAGCACCTTC AGCAC 3'; FRITZ forward 5' CAGTAGT GGAGGTGAAGGAG 3', reverse 5' GAGTC CAAGATGACGAAG 3'; PTC forward 5' CCCCAACAAAAATTCAACC 3', reverse 5' CATCATCCACACCAACACC 3'; Jagged-1 forward 5' GGACTATGAGGGCAAGAAC 3', reverse 5'CCTTTCCACCCATTTTTAC 3'; and ubiquitin forward 5' GTTGATCTTT GCTGGAAAAC 3', reverse 5' AATGCCTTC CTTGTCCTG 3'.

STATISTICAL ANALYSIS

All results are expressed as mean (SEM). Statistical comparisons were performed using a non-parametric Mann-Whitney U test. Statistical analysis was performed using Statview 4.5.1 (Abacus Concepts California, USA) and regression plots were generated using KaleideGraph 3.0 (Synergy Software, Pennsylvania, USA).

\section{Results}

GENE PROFILING OF PBC

Clustering of genes based on their relative expression (fig 2) indicated gene groups that were similarly upregulated or downregulated and was a rapid screen for gene groups of interest. This clustering analysis revealed that greater than $70 \%$ of genes had a similar pattern of expression in PBC and PSC associated cirrhosis compared with non-diseased tissue. 


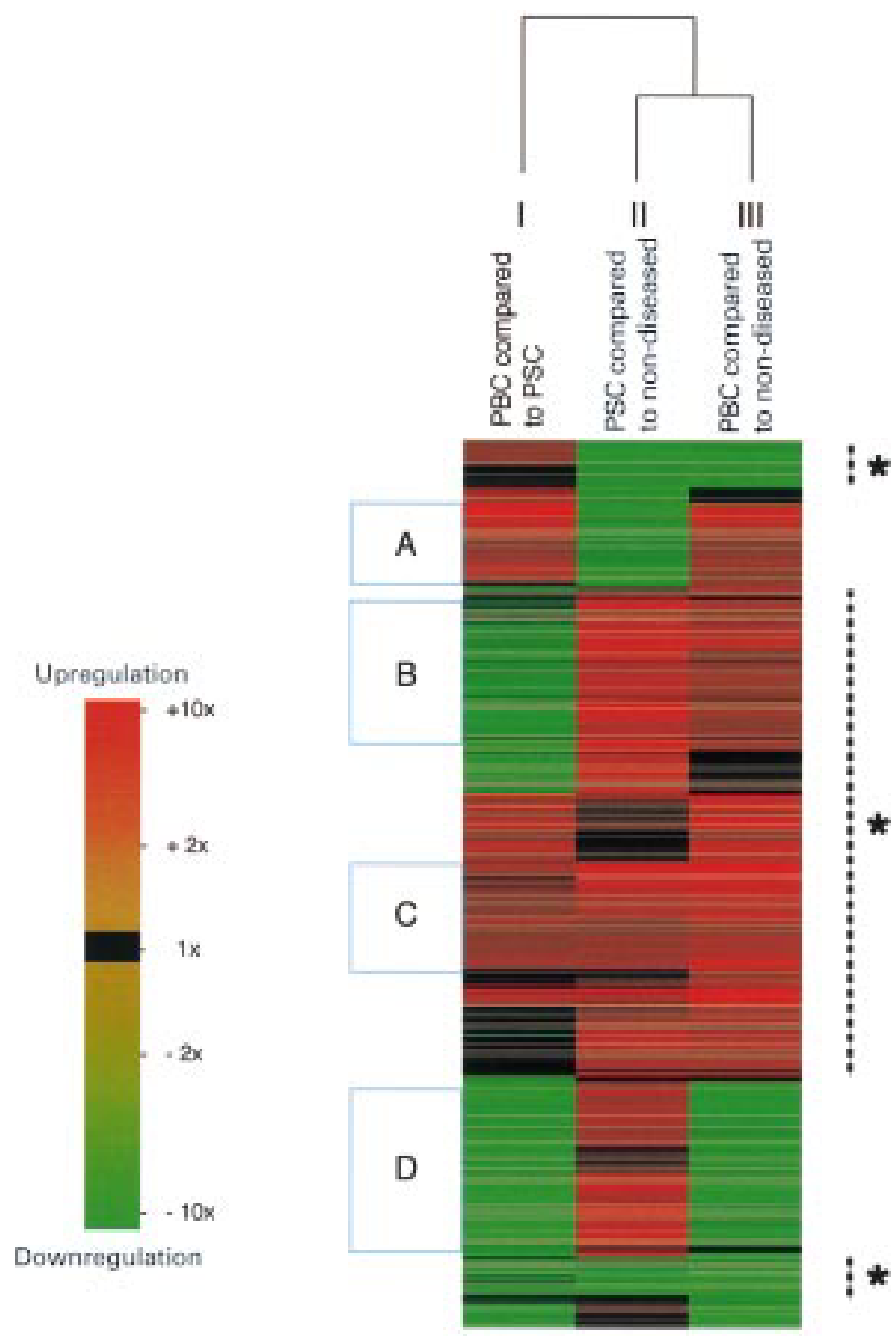

Figure 2 Clustering of the 874 genes. Each line across all comparisons represents a single gene with upregulation indicated in increasing red and downregulation indicated in increasing green. Genes were clustered according to the nature and extent of their differential expression over the three comparisons. There was more than $70 \%$ similarity in the patterns of expression in primary biliary cirrhosis (PBC) and primary sclerosing cholangitis (PSC) associated cirrhosis compared with non-diseased tissue (indicated by the broken lines with asterisks). This graphical depiction of the data identifies groups of genes, such as those that had increased expression in: PBC compared with both non-diseased tissue and PSC associated cirrhosis $(A)$; both PBC and PSC associated cirrhosis compared with non-diseased liver $(B, C) ; P B C$ compared with PSC associated cirrhosis in addition to both of these diseases compared with non-diseased liver $(C)$; and PSC but not PBC compared with non-diseased liver (D).

Although the patterns of gene expression were similar, there were differences in the degree of differential gene expression of both PBC and PSC associated cirrhosis compared with nondiseased tissue. All differential expression data are depicted by colour intensity in both fig 2 and the supplemental material clustering figure (please see website for supplemental data, at www.gutinl.com). Additionally, the supplemental material clustering figure includes the vertical (gene) dendrogram labelled with individual gene names.

\section{extra}

website

Additional data appear on the Gut website

www.gutjnl.com levels were greater in PBC than in either nondiseased or PSC associated cirrhotic liver (supplemental material-see website). Brain derived neurotrophic factor (BDNF) receptor (Trk3), protein serine/threonine kinase 1, stem cell protein (SCL or TAL-1), and Wnt-2 were greatly increased in both PBC and PSC associated cirrhosis compared with non-diseased tissue (supplemental material-see website). Ephrin A3 was the most strikingly downregulated gene and migration inhibitory factor related protein 8 (MRP-8/calgranulin $\mathrm{A})$ and the receptor for cytotoxic tumour necrosis factor related apoptosis inducing ligand were markedly downregulated in both PBC and PSC associated cirrhosis (supplemental material—see website).

Gene upregulation at 2.0 -fold or greater is presented in figs 3 and 4 . The supplemental material tables list genes that exhibited 1.5-fold or greater differential expression while the entire cDNA array differential expression data is in the supplemental material clustering figure (see website).

DIFFERENTIAL EXPRESSION IN PBC COMPARED WITH NON-DISEASED LIVER

Inflammation (fig $3 \mathrm{~A}$ ).

CXCR4 and flt3 receptor were the most dramatically increased inflammation associated genes, each with greater than sixfold increases in expression in PBC compared with non-diseased tissue. Neither a Th1 nor a Th2 predominant cytokine response was observed. The Th2 associated cytokines IL-4, IL-5, and IL-13 and the Th1 associated molecules lymphotoxin-beta, IFN- $\gamma$ receptor beta subunit, and tumour necrosis factor receptors were increased in PBC compared with non-diseased liver. Increased expression in PBC of the chemokines CXCR4 and MCP-1 was observed. CXCR4, flt3 receptor, myeloid cell nuclear differentiation antigen, IL-3, IL-5, IL-15, IL-17, and granulocyte-macrophage colony stimulating factor were upregulated greater than threefold in PBC compared with non-diseased liver.

Fibrosis (fig 3B).

The most dramatic increases in the fibrosis category were CTGF and TGF-beta3, which were increased greater than 10-fold in PBC. Notably, platelet activating factor receptor, FGF receptor 1, FGF receptor 3, cysteine rich FGF receptor, acidic FGF, and PDGF receptor were increased in PBC. Interestingly, upregulated mediators of fibrosis included several TGF family members, TGF-beta3, TGFbeta2, and TGF-beta1 (1.5-fold, see supplemental material at the website). Importantly, recognised fibrotic mediators such as EMMPRIN were increased in PBC (1.7-fold, see supplemental material at the website). Clearly, integrin alpha 5 and 6 (VLA-5 and 6; CD49e and CD49f), which we categorised under inflammation (fig 3A), are also implicated in fibrogenesis. 
A *Stromal cell derived factor 1 receptor (SDF-1 receptor, CXCR4) Tyrosine protein kinase receptor flt; CD135 Myeloid cell nuclear differentiation antigen (MNDA) *Interleukin $3(\mathrm{IL}-3)$ *Interleukin 5 (IL-5)

Granulocyte macrophage colony stimulating factor (GM-CSF R alpha) Lymphotoxin beta (LT-beta; LTB) Interleukin 1 lnterleukin 13 (IL-13) Interleukin 1 alpha (IL-1 alpha; IL1A) Interferon gamma (IFN-gamma) receptor beta subunit Monocyte chemotactic protein 1 (MCP1) C5a anaphylatoxin receptor (C5AB) Interferon consensus sequence binding protein (ICSBP) Interleukin 14 (IL-14) Integrin alpha 6; VLA6; CD49f Interleukin 7 receptor alpha subunit (IL-7R-alpha; IL7R) Tumour necrosis factor receptor (TNFR) PAI3; plasminogen activator inhibitor 3 (PLANH3) CD40 ligand (CD40-L) Integrin alpha 5; VLA5; CD49e

B

${ }^{*}$ Connective tissue growth factor (CTGF)
$*$ Transforming growth factor beta 3 (TGF-beta3) Platelet activating factor receptor (PAFR)
Plactor Transforming growth factor beta2 (TGF-beta 2) Transforming growth factor alpha (TGF-alpha) *Fibroblast growth factor receptor 3 (FGFR3) *Thrombin receptor (TR); F2R; PAR $\mathrm{N}$-sam; fibroblast growth factor receptor1 (FGFR1; bFGFR) Cysteine rich fibroblast growth factor (FGF) recepto Platelet derived growth factor receptor beta subunit (PDGFRB)

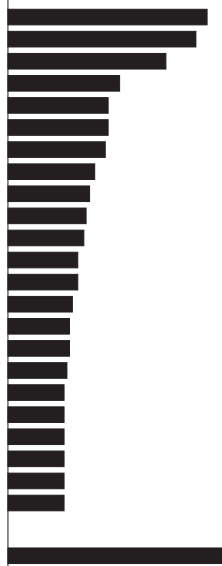

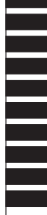

*Early response protein NAK1; TR3 orphan receptor ${ }^{*}$ Caspase 2 (CASP2) **Inhibitor of apoptosis protein 2 (IAP2 $\mathrm{Bcl}-2$ homologous antagonist/killer (BAK) ${ }^{* *}$ Caspase 6 (CASP6)

**Inhibitor of apoptosis protein 1 (IAP1) **BCl-2 related protein A1 (Bcl-2A1; BFL1) **Bcl-2 adenovirus E1B $19 \mathrm{kD}$ interacting protein (NIP1) ${ }^{*} \mathrm{Bcl}-2$ interacting killer (BIK) **Receptor interacting protein; cell death protein RIP **Inhibitor of apoptosis protein 3 (IAP3) Apoptosis regulator box $* *$ WSL protein + TRAMP + Apo-3 + death domain receptor 3 (DDR3
Caspase 8 (CASP8
Early response protein NAK1; TR3 orphan recepto $* *$ WSL protein + TRAMP + Apo-3 + death domain receptor 3 (DDR3
Caspase 8 (CASP8
Early response protein NAK1; TR3 orphan recepto ${ }^{* *}$ Cysteine protease ICE-LAP3 $\begin{array}{lllllllllll}0 & 1 & 2 & 3 & 4 & 5 & 6 & 7 & 8 & 9 & 10\end{array}$ Fold increased expression

PBC associated cirrhosis compared with non-diseased liver $\square$ PSC associated cirrhosis compared with non-diseased liver

Figure 3 Upregulation of inflammatory, fibrosis, and apoptosis associated genes. Inflammation associated genes (A), fibrosis associated genes (B), and apoptosis associated genes $(C)$ that were upregulated 2.0 -fold or greater in primary biliary cirrhosis $(P B C)$ compared with non-diseased liver tissue. Apoptosis associated gene upregulation of 2.0-fold or greater in primary sclerosing cholangitis (PSC) associated cirrhosis compared with non-diseased liver tissue is also shown (D). Genes marked with an asterisk were upregulated greater than twofold in PBC compared with both non-diseased liver tissue and PSC associated cirrhosis ( $\left.{ }^{\star} A-C\right)$. Genes marked with two asterisks were upregulated greater than twofold in PSC associated cirrhosis compared with both non-diseased liver tissue and $P B C\left({ }^{\star} D\right)$.

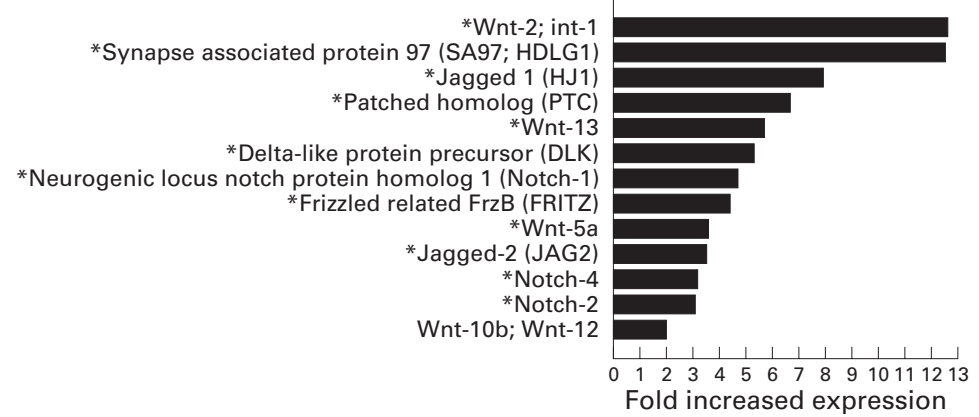

Figure 4 Upregulation of Drosophila homologues. Drosophila homologues that were upregulated 2.0-fold or greater in primary biliary cirrhosis (PBC) compared with non-diseased liver tissue. Genes marked with an asterisk were upregulated greater than twofold in PBC compared with both non-diseased liver tissue and primary sclerosing cholangitis associated cirrhosis.
Regeneration, growth, and proliferation (supplemental material — see website)

Expression of many highly conserved genes of the Wnt and notch pathways and four neurotrophin associated genes were increased in PBC. Indeed, of the 16 genes in this category that exhibited greater than threefold increases in expression, 13 were either Drosophila homologues (fig 4) or neural genes. The Drosophila homologues included Wnt-2, Wnt-13, Wnt-5a, and Wnt-10b/Wnt-12 of the Wnt pathway, and Jagged-1, Jagged-2, notch-1, notch-2, and notch-4 of the notch pathway (fig 4). The upregulated neurotrophin associated genes were BDNF receptor/Trk3, BDNF, glial cell line derived neurotrophic factor (GDNF), and ret proto-oncogene (part of the GDNF receptor complex) (supplemental material-see website). Many genes of the insulin growth axis such as insulin-like growth factor binding protein (IGFBP)-6, IGFBP-2, and insulin receptor, were increased in PBC. Furthermore, cyclin-D1, cyclin dependant kinase inhibitor (CDKN)-1C, CDKN-1A, and CDKN-3 were increased in PBC. Delta-like protein, ataxia telangiectasia, Erb B4, CDKN-1C, and IGFBP-6 were increased threefold or greater in PBC compared with non-diseased tissue.

Intracellular signalling and nuclear (supplemental material-see website).

Synapse associated protein 97 and stem cell protein (SCL or Tal-1) were increased greater than ninefold in PBC. Many genes involved in intracellular signalling pathways had increased expression in PBC. They included genes that are recognised downstream targets of Wnt signalling, including c-jun, c-myc, c-fos related antigen 1 , and beta-catenin. Many transcription factors including helix-loop-helix protein HLH 1R21 and zinc finger in the multiple endocrine neoplasia 1 locus and mediators of several pathways, including the Erb B pathway, of which transducer of Erb B2 is a component, were increased in PBC.

\section{Stress responseloxidative stress (supplemental} material-see website)

The stress response was characterised by increased expression of the heat shock proteins (HSP)70.1, HSP90A, and HSP27 and genes involved in oxidative stress including glutathione-S-transferase $\mathrm{M} 1$, dioxin inducible cytochrome P450 1B1, and cytosolic superoxide dismutase 1 .

\section{Uncategorised genes (supplemental material—see} website)

Many genes were not categorised because they have either multiple or poorly characterised functions. Follistatin, prorelaxin- $\mathrm{H} 2$, and ephrin associated genes including ephrin type $\mathrm{B}$ receptors 2 and 3 and ephrin type A receptor 3 had greater expression in PBC. Retinoic acid binding protein II could be considered fibrosis associated but genes such as this, where the cell of origin of the mRNA is unknown, were uncategorised. 
Apoptosis genes (fig 3C)

Only the proapoptotic early response protein NAK1/TR3 orphan receptor ${ }^{29}$ was increased greater than twofold in PBC.

DIFFERENTIAL EXPRESSION IN PBC COMPARED WITH PSC

Gene upregulation in PBC compared with PSC associated cirrhosis helped identify genes preferentially involved in the pathogenesis of PBC compared with another type of "biliary" cirrhosis. The inflammation associated genes IL-3, IL-4, IL-5, IL-15, IL-17, and CXCR4 had greater expression in PBC compared with PSC associated cirrhosis (fig 3A). CTGF and TGF-beta3 expression was greater in PBC than in PSC associated cirrhosis (fig 3B).

Many mammalian homologues of highly conserved genes involved in growth and regeneration originally identified in Drosophila were increased in PBC compared with PSC associated cirrhosis. These included FRITZ, Wnt13, Wnt-5a, notch-1, notch-2, notch-4, Jagged-1, Jagged-2, and smoothened (fig 4). Additionally, the GDNF receptor ret was increased in PBC compared with PSC. Differential expression was seen in some stress related genes, notably HSP27.

Data on cytoplasmic signalling and nuclear associated genes revealed striking differences between PBC and PSC associated cirrhosis. An increase of greater than 80-fold of transcription initiation factor $250 \mathrm{kDa}$ subunit (TAFII250) was seen in PBC compared with PSC associated cirrhosis. Interestingly, expression of c-src, Rad52, and c-myb was greater in PBC compared with PSC. In contrast, some signalling associated genes such as neural-cadherin and several oncogenes, such as SnoN and p56lck, were markedly upregulated in PSC compared with PBC (supplemental material-see website)

Notable uncategorised genes that exhibited greater expression in PBC compared with PSC were follistatin, FRITZ, prorelaxin $\mathrm{H} 2$, renin binding protein, angiotensin II type $1 \mathrm{~A}$ receptor, and thrombomodulin.

An interesting difference between PBC and PSC associated cirrhosis was that in contrast with PBC, many apoptosis associated genes were upregulated in PSC (fig 3D). These included inhibitor of apoptosis protein (IAP)-1, IAP-2, IAP-3, four anti-apoptotic $\mathrm{Bcl}-2$ related proteins, $\mathrm{Bcl}-2, \mathrm{Bcl}-2 \mathrm{~A} 1, \mathrm{Bcl}-\mathrm{x}$, and $\mathrm{Bcl}-2$ adenovirus E1B $19 \mathrm{kDa}$ interacting protein, and the pro-apoptotic molecules Bak, Bik, and Bax of the Bcl-2 family.

STATISTICAL ANALYSIS OF ARRAY DATA

Correlation coefficients following regression analysis for the ATLAS Human Gene Array and ATLAS Cytokine Receptor Array data were, respectively: PBC compared with normal liver $r^{2}=0.77$ and 0.85; PBC compared with donor liver $r^{2}=0.84$ and 0.93; and $\mathrm{PBC}$ compared with PSC $r^{2}=0.86$ and 0.85 , with $\mathrm{p}<0.001$ for all three comparisons.

There were 190 genes common to both cDNA arrays. With the four probes on the two arrays there was a strong correlation of the 760 duplicate signals $\left(r^{2}=0.76, \mathrm{p}<0.001\right)$. Similarly, the 760 duplicate signals were compared by subtracting the regression ratio determined in comparisons of PBC or PSC associated cirrhosis with non-diseased tissue. The 760 duplicate signals showed a mean difference of only 0.084 (0.017).

The two methods of determining differential gene expression were compared by subtracting, for each gene, the ratio determined by regression analysis from the ratio determined by adjustment for ubiquitin expression (see methods). The three comparisons, of PBC with normal, donor, and PSC, used a total of 2359 determinations of differential gene expression and found that the mean difference between the two methods was $0.29(0.058)$ ratio units. In addition, we subtracted, for each gene, the ratios generated by the donor and normal liver samples when each were compared with PBC. The 1572 duplicate comparisons showed a mean difference between donor and normal liver of only $0.10(0.058)$ ratio units, indicating the close similarity of the two types of non-diseased liver.

\section{QUANTITATIVE RT-PCR}

Increased expression of 10 selected genes, mainly genes associated with fibrosis and the Wnt pathway, was confirmed on individual patient specimens, including all specimens analysed on the cDNA arrays (fig 5). Gene expression was quantified by real time RT-PCR twice on two separate cDNA syntheses. CTGF was the most abundantly expressed gene with $4.6 \times 10^{6}\left(0.4 \times 10^{6}\right)$ relative gene copies per $\mu \mathrm{g}$ of total RNA in PBC. Wnt-13 was the least abundant transcript quantified, with only 64 copies per $\mu \mathrm{g}$ of total RNA in non-diseased liver. The cDNA arrays comparing PBC with nondiseased liver showed increases of $13.6 \times$ for CTGF, $7.2 \times$ for CXCR4, $1.7 \times$ for EMMPRIN, $10.7 \times$ for follistatin, $5.7 \times$ for Wnt-13, 3.6× for Wnt-5a, 1.8× for betacatenin, $4.4 \times$ for FRITZ, $7.9 \times$ for Jagged-1, and $6.7 \times$ for PTC. Thus the array and RT-PCR data were concordant.

\section{Discussion}

Intrahepatic cDNA array analysis is a new approach to the study of gene expression in cirrhosis. Utilising this approach we have identified many novel interesting differences at the mRNA level in the molecular pathways of PBC by comparison with non-diseased liver and PSC associated cirrhotic liver. Identifying differential expression of genes associated with inflammation, fibrosis, apoptosis, proliferation, regeneration, neural cells, and the Wnt and notch pathways enabled identification of molecular pathways that may be involved in PBC pathogenesis.

The novel observations of differential expression included many genes of the Wnt and notch pathways, both pathways being highly conserved and initially identified in Drosophila development and differentiation. The observations are consistent with increased Wnt signalling rather than increased turnover of Wnt 
pathway components. In addition to the downstream increase in beta-catenin expression, most of the genes classically activated by the Wnt pathway were increased in PBC, including c-myc, c-jun, c-fos related antigen 1 , and cyclin-D1. The exact function of the Wnt pathway in cirrhosis is unknown. Multiple Wnt pathway genes have been implicated in tumorigenesis but the incidence of hepatocellular carcinoma in PBC is less than in other types of cirrhosis. The physiological role of the Wnt pathway in adult organs is poorly understood. The Wnt response transcription factor $\mathrm{T}$ cell factor 4 is greatly expressed in normal adult liver but its physiological function there is unknown. ${ }^{30}$ Differentiation of haematopoietic progenitor cells involves Wnt pathway genes, ${ }^{31}$ mesenchymal to epithelial conversion in the metanephros requires Wnt expression, ${ }^{32}$ and a regulator role for the Wnt pathway and $\mathrm{T}$ cell factor 4 in differentiation within the vertebrate gut epithelium is likely. ${ }^{30}$ Replacement of the resident fibroblast population in the synovium of rheumatoid arthritis patients with immature bone marrow and mesenchymal cells is accompanied by increased Wnt-5a/Fz5 expression. ${ }^{33}$ The increased expression of Wnt-5a, FRITZ, and beta-catenin in PBC, PSC, and HCV cirrhosis (fig 5) suggests that the Wnt pathway is active in all forms of cirrhosis. However, the frequency of Wnt pathway gene detection in PBC suggests that it may play a more specific role in PBC pathogenesis (fig 4). Clearly a more detailed examination of the Wnt pathway in cirrhosis is needed.
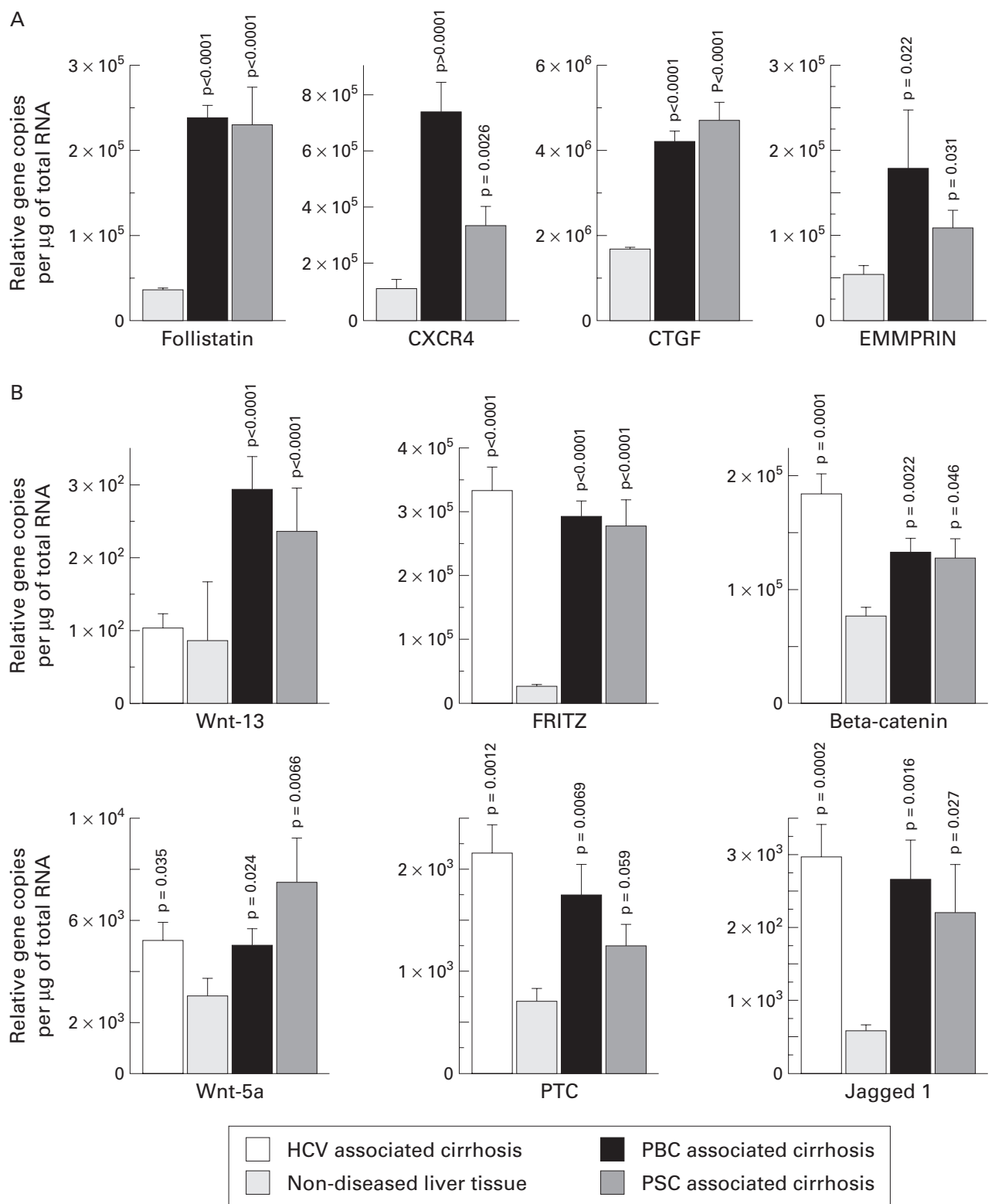

Figure 5 Differential gene expression examined by reverse transcriptase-polymerase chain reaction (RT-PCR). Quantitative real-time RT-PCR data (mean (SEM)) on $m R N A$ from primary biliary cirrhosis $(P B C)(n=6)$, primary sclerosing cholangitis (PSC) associated cirrhosis $(n=4)$, hepatitis $C$ virus $(H C V)$ cirrhosis $(n=6)$, and non-diseased donor liver $(n=4)$. The depicted differential expression data are in two groups: (A) follistatin, $C X C$ chemokine receptor 4 (CXCR4), connective tissue growth factor (CTGF), and extracellular matrix metalloproteinase inducer (EMMPRIN) and (B) Drosophila homologues including Wnt-13, secreted frizzled related protein 3 (FRITZ), beta-catenin, and fagged -1 . 
The notch (receptor)/Jagged (ligand) pathway has been partially characterised in human disease. ${ }^{34}$ Mutations in the Jagged-1 gene are responsible for Alagille syndrome. ${ }^{35}$ Jagged-1 expression in the adult liver is localised to zone three hepatocytes and biliary epithelium. ${ }^{36}$ Notch-1, -2 , and -3 as well as Jagged-1 and -2 are implicated in the determination of both gamma-delta and alpha-beta $T$ cells as well as the $\mathrm{CD}^{+}$versus $\mathrm{CD}^{+}$thymocyte lineage choice. ${ }^{37}{ }^{38}$ The cell fate determination function that the Wnt and notch pathways share is partially explained by the interaction of Wnt proteins with notch receptors and the binding of the regulatory protein dishevelled to both frizzled and notch receptors. ${ }^{39} 40$ The observed Wnt and notch pathway differential gene expression relationship to $\mathrm{PBC}$ pathogenesis remains to be determined.

A documented function of Wnt and notch pathways is regulation of the growth and regeneration related molecules, follistatin and activin. It is therefore of interest that follistatin and activin were increased in both PBC and PSC associated cirrhosis. Wnt and FGF expression inhibit activin activity while the Wnt and notch pathways may regulate follistatin. ${ }^{41}{ }^{42}$ Intrahepatic follistatin stimulates proliferation and is antiapoptotic. Follistatin can accelerate liver regeneration following partial hepatectomy. ${ }^{43}{ }^{44}$ Conversely, activin is an autocrine inhibitor of hepatocyte DNA synthesis, ${ }^{45}$ retards hepatocyte proliferation, and functions in the maintenance of constant liver mass. ${ }^{46}$ Follistatin is an activin binding protein and generally the effects of follistatin are antagonised by activin. ${ }^{47}$ Activin infused intravenously leads to apoptosis around the central vein of the hepatic lobule, an effect ablated by adding follistatin. ${ }^{49}$ The mechanism of follistatin mediated control of liver growth is not understood. EGF, TGF-beta, phenylephrine, and glucagon, all of which are known to influence hepatocyte regeneration, upregulate follistatin mRNA expression in hepatocytes. ${ }^{50}$ The possible relationship of the Wnt, notch/ jagged, and follistatin/activin pathways may be a common link in influencing hepatocyte proliferation, either specifically in PBC or more generally in any form of cirrhosis. cDNA array technology is an unparalleled means of simultaneously examining the mRNA expression of potentially functionally linked genes such as those of the Wnt, notch/jagged, and follistatin/ activin pathways in hepatocyte proliferation.

A principle feature of $\mathrm{PBC}$ is intrahepatic inflammation. PBC was characterised by our cDNA array analysis as involving a mixed Th1 and Th2 immune response. Previous studies have generally suggested that PBC predominantly involves a Th1 response. ${ }^{51}$ In situ hybridisation studies in PBC patients ${ }^{9}$ and an animal model of $\mathrm{PBC}^{52}$ have shown increased IFN- $\gamma$ expression consistent with a Th1 response. However, mixed Th1 and Th2 cytokine expression has been observed in a different animal model of $\mathrm{PBC}^{53}$ and we previously demonstrated significant increases in intrahepatic IL-2, IL-6, IL-8, and TGF-beta expression in PBC. ${ }^{10}$ Furthermore, PBC patient derived peripheral $\mathrm{T}$ cell clones are heterogenous for Th1/Th2 profile. ${ }^{16}$ Examining few cytokines may misrepresent the Th1/Th2 profile. Our data highlight the principle strength of cDNA array analysis in simultaneously examining expression of many genes.

Fibrosis associated gene expression was well defined by cDNA array analysis. Increases in growth factors such as FGF-1 and FGF-3 in PBC are consistent with known pathways of both paracrine and autocrine stimulation of HSCs. ${ }^{54}$ Biliary epithelial cells and hepatocytes, in response to the immune mediated damage or cytokine signals such as MCP-1, are likely additional sources of these profibrotic molecules. ${ }^{55}$ The increased expression of TGFbeta 2 and 3 concords with evidence that all TGF-beta isoforms mediate hepatic fibrosis. ${ }^{56}$ TGF-beta, CTGF, and EMMPRIN were upregulated in both PBC and PSC (fig 3B). CTGF is a HSC product released following stimulation by TGF-beta, so their linked differential expression was expected. ${ }^{23} 58$ In contrast, EMMPRIN is not known to be a fibrotic mediator of human cirrhosis. EMMPRIN is expressed by tumour and epithelial cells and interacts with fibroblasts resulting in increased expression of MMP-1, MMP-2, (collagenase) and MMP-3 (stromelysin 1). ${ }^{59-63}$

The above discussion has primarily focussed on differential gene expression in PBC compared with non-diseased liver. Such differential expression may be generally involved in cirrhosis or inflammation rather than be specific for PBC. Therefore, PBC was compared with another "biliary" cirrhosis, PSC. The overall gene profile data indicate that regulation of liver gene expression in these two diseases is somewhat similar with $70 \%$ of examined genes similarly expressed. However, there were differences consistent with differing pathogenic pathways in PBC. Most notable was the dramatic difference in expression of apoptosis associated genes between the two types of cirrhosis. This difference is consistent with apoptosis being more active and actively regulated in PSC associated cirrhosis than in PBC. There have been no direct comparisons of apoptosis between PBC and PSC. Apoptosis and cellular proliferation are clearly linked processes. Presently, studies have not implicated apoptosis in the proliferative response of PBC. However, abnormal apoptosis leading to persistence of dysplastic biliary epithelial cells is thought to be involved in the pathogenesis of cholangiocarcinoma complicating PSC. ${ }^{64}$

Intracellular signalling arising from growth and differentiation responses is clearly important in the pathogenesis of human liver disease. The observed signalling associated differential gene expression was consistent with a PBC specific transcription associated gene profile. Greater TAFII250 expression in PBC than both non-diseased and PSC liver is intriguing. TAFII 250 is a TATA box binding protein associated factor (TAF) that participates in the transcription factor TFIID assembly for transcription of cyclin genes, especially cyclin A 
and cyclin D1. ${ }^{65}$ Cell lines without normal TAFII250 function arrest in G1 and transcription of cyclin genes is arrested ${ }^{66}$ Why such a dramatic difference in TAFII250 expression is seen in PBC is unclear and warrants further study.

Detection of intrahepatic expression of neural genes was expected given the emerging connection of such genes with HSC differentiation. However, the large number of such genes identified was interesting. Novel differential expression of the neural genes Trk3, GDNF, ret, and synapse associated protein 97 was observed. Trk3, the BDNF receptor, which was increased in both PBC and PSC, is neurotrophin (NT) associated. The NT associated proteins include the ligands nerve growth factor (NGF), NT-3, NT-4, NT-6, and GDNF, and the receptors TrkB, TrkC, and the NGF receptor p75NTR. ${ }^{67}$ GDNF has not been studied in liver but is implicated in development; mutations in its receptor ret are responsible for multiple endocrine neoplasia 2 and Hirschsprung disease. ${ }^{68-70}$ NTs are not neural cell specific; T cells, B cells, and macrophages produce NTs during inflammation. ${ }^{71-73}$ Increased expression of neural markers might also reflect nerve formation accompanying the increased angiogenesis in cirrhosis. However, the cellular origin of differentially expressed neural genes in liver may originate from HSCs, which have a neural phenotype that includes expression of $\mathrm{p} 75 \mathrm{NTR}$ and may originate from the neural crest. ${ }^{54} 74-79$

A number of caveats relate to the use of cDNA arrays and experiments on whole liver tissue. The cDNA array data are expressed numerically and the statistical analyses convey its precision and reproducibility. However, the strength of this technique is the identification of differentially expressed genes rather than quantification of individual gene expression. To quantify and confirm increased individual gene expression, techniques such as northern blot or quantitative RT-PCR are required. ${ }^{80} 81$ Hepatocytes are the major contributant to preparations of whole liver mRNA. However, other cell types such as biliary epithelial cells, hepatic stellate cells, endothelial cells, Kupffer cells, $\mathrm{T}$ cells, and macrophages probably make significant contributions. In PBC with bile duct loss the proportion of the total mRNA pool derived from biliary epithelium is unknown. Genes expressed specifically by one cell type may be significantly differentially expressed despite small cDNA array ratios. Future studies will analyse mRNA from isolated subpopulations of cells. Such studies require careful interpretation because isolation methods may activate cells, especially when cell culture is involved, and removes interactions that are present in the solid organ, such as those with other cell types and the extracellular matrix. Additionally, differential expression of a mRNA need not lead to the differential expression of its corresponding biologically active protein.

In conclusion, the data presented here are a significant advance in documenting many new observations and multiple simultaneous observations of differential gene expression in PBC in both novel and previously identified pathogenic pathways. A number of these genes have been studied in vitro or in vivo in experiments unrelated to liver pathophysiology. However, given the central roles of the genes we have discussed in processes with hepatic equivalents such as inflammation, fibrosis, apoptosis, signalling, proliferation, and regeneration, they are very likely important in the pathogenesis of PBC. Many genes, such as EMMPRIN, CXCR4, follistatin, and CTGF, were associated with cirrhosis irrespective of aetiology. The use of PSC as a cirrhotic biliary inflammatory comparison helped identify genes potentially important in the differential pathogenesis of PBC and PSC. Finally, the observed differential gene expression of the Wnt and notch pathways particularly implicates these highly conserved Drosophila pathways in PBC pathogenesis. This is the first time the Wnt pathway has been implicated in any form of cirrhosis. Future studies will require localisation of gene expression and a direct analysis of function in pathways related to liver pathobiology.

The Wellcome Foundation and the Clive and Vera Ramaciotti Foundation funded the purchase of a Model 7700 Sequence Detector. N Shackel is a recipient of a National Health and Medical Research Council of Australia Sir Gustav Nossal Scholarship.

1 Gershwin ME, Ansari AA, Mackay IR, et al. Primary biliary cirrhosis: an orchestrated immune response against epitheial cells. Immunol Rev 2000;174:210-25.

2 Mackay IR, Whittingham S, Fida S, et al. The peculiar autoimmunity of primary biliary cirrhosis. Immunol Rev 2000;174:226-37

3 Yeaman SJ, Kirby JA, Jones DEJ. Autoreactive responses to pyruvate dehydrogenase complex in the pathogenesis of primary biliary cirrhosis. Immunol Rev 2000;174:238-49.

4 Joplin R, Gershwin ME. Ductular expression of autoantigens in primary biliary cirrhosis. Semin Liver Dis 1997;17: 97-103.

$5 \mathrm{Xu} \mathrm{L}$, Guo L, Keogh A, et al. Isolation and characterisation of a novel virus associated with primary biliary cirrhosis. Hepatology 2000;32:A550.

6 Krams SM, Van de Water J, Coppel RL, et al. Analysis of hepatic T lymphocyte and immunoglobulin deposits in patients with primary biliary cirrhosis. Hepatology 1990;12: patients with

7 Hashimoto E, Lindor KD, Homburger HA, et al. Immunohistochemical characterization of hepatic lymphocytes in primary biliary cirrhosis in comparison with primary sclerosing cholangitis and autoimmune chronic active hepatitis. Mayo Clin Proc 1993;68:1049-55.

8 Yasoshima M, Nakanuma Y, Tsuneyama K, et al. Immunohistochemical analysis of adhesion molecules in the microenvironment of portal tracts in relation to aberrant expression of PDC-E2 and HLA-DR on the bile ducts in primary biliary cirrhosis. F Pathol 1995;175:319-25.

9 Harada K, Van de Water J, Leung PS, et al. In situ nucleic acid hybridization of cytokines in primary biliary cirrhosis: predominance of the Th1 subset. Hepatology 1997;25:7916 .

10 Napoli J, Bishop GA, McCaughan GW. Increased intrahepatic messenger RNA expression of interleukins 2,6 , and 8 patic messenger RNA expression of interleukins 2, 6, and

11 Palmer JM, Diamond AG, Yeaman SJ, et al. T cell responses to the putative dominant autoepitope in primary biliary to the putative dominant autoepitope in primary
cirrhosis (PBC). Clin Exp Immunol 1999;116:133-9.

12 Teoh KL, Mackay IR, Rowley MJ, et al. Enzyme inhibitory autoantibodies to pyruvate dehydrogenase complex in primary biliary cirrhosis differ for mammalian, yeast and bacterial enzymes: implications for molecular mimicry. Hepatology 1994;19:1029-33.

13 Baum H. Mitochondrial antigens, molecular mimicry and autoimmune disease. Biochim Biophys Acta 1995;1271: $111-21$

14 Fussey SP, Ali ST, Guest JR, et al. Reactivity of primary biliary cirrhosis sera with Escherichia coli dihydrolipoamide acetyltransferase (E2p): characterization of the main immunogenic region. Proc Natl Acad Sci USA 1990;87: 3987-91.

15 Van de Water J, Ansari AA, Surh CD, et al. Evidence for the targeting by 2 -oxo-dehydrogenase enzymes in the $\mathrm{T}$ cell response of primary biliary cirrhosis. F Immunol 1991;146: 89-94.

16 Van de Water J, Ansari A, Prindiville T, et al. Heterogeneity of autoreactive $\mathrm{T}$ cell clones specific for the E2 component 
of the pyruvate dehydrogenase complex in primary biliary cirrhosis. F Exp Med 1995;181:723-33.

17 Van de Water J, Turchany J, Leung PS, et al. Molecular mimicry in primary biliary cirrhosis. Evidence for biliary epithelial expression of a molecule cross-reactive with pyruvate dehydrogenase complex-E2. F Clin Invest 1993 91:2653-64.

18 Joplin R. Isolation and cloning of antimitochondrial antibodies. In: Lindor KD, Heathcote EJ, Poupon R, eds. Primary biliary cirrhosis: from pathogenesis to clinical treatment. Dordrecht: Kluwer Academic Publishers, 1997:1923.

19 Milani S, Herbst H, Schuppan D, et al. Transforming growth factors beta 1 and beta 2 are differentially expressed growth factors beta 1 and beta 2 are differentially expressed

20 Schuppan D, Hahn EG. Fibrogenesis in PBC. In: Lindor KD, Heathcote EJ, Poupon R, eds. Primary biliary cirrhosis: from pathogenesis to clinical treatment. Dordrecht: Kluwer Academic Publishers, 1997:64-75.

21 Joplin R, Hishida T, Tsubouchi $\mathrm{H}$, et al. Human intrahepatic biliary epithelial cells proliferate in vitro in response to human hepatocyte growth factor. 7 Clin Invest 1992;90:1284-9.

22 Matsumoto K, Fujii H, Michalopoulos G, et al. Human biliary epithelial cells secrete and respond to cytokines and hepatocyte growth factors in vitro: interleukin-6, hepatocyte growth factor and epidermal growth factor promote cyte growth factor and epidermal growth factor prom

23 Paradis V, Dargere D, Vidaud M, et al. Expression of connective tissue growth factor in experimental rat and human liver fibrosis. Hepatology 1999:30:968-76.

24 Shields PL, Morland CM, Salmon M, et al. Chemokine and chemokine receptor interactions provide a mechanism for selective $\mathrm{T}$ cell recruitment to specific liver compartments within hepatitis C-infected liver. F Immunol 1999;163: 6236-43.

25 Sambrook J, Fritsch EF, Maniatis T. Selection of poly(A)+ RNA. Molecular cloning - A laboratory manual. Cold Spring Harbor: Cold Spring Harbor Laboratory Press, 1989;7:269.

26 Cristofalo VJ. A DNA chip off the aging block. Nat Med 2000;6:507.

27 Eisen MB, Spellman PT, Brown PO, et al. Cluster analysis and display of genome-wide expression patterns. Proc Nat Acad Sci USA 1998;95:14863-8.

28 Morrison TB, Weis JJ, Wittwer CT. Quantification of low-copy transcripts by continuous SYBR Green I monitoring during amplification. Biotechniques 1998;24 954-8, 960, 962 .

29 Uemura H, Chang C. Antisense TR3 orphan receptor can increase prostate cancer cell viability with etoposide treatment. Endocrinology 1998;139:2329-34.

30 Lee YJ, Swencki B, Shoichet S, et al. A possible role for the high mobility group box transcription factor TCF-4 in verhigh mobility group box transcription factor TCF-4 in vertebrate gut ep

31 Van Den Berg DJ, Sharma AK, Bruno E, et al. Role of members of the Wnt gene family in human hematopoiesis. Blood 1998;92:3189-202.

32 Barasch J, Yang J, Ware CB, et al. Mesenchymal to epithelial conversion in rat metanephros is induced by LIF. Cell 1999;99:377-86.

33 Sen M, Lauterbach K, El-Gabalawy H, et al. Expression and function of wingless and frizzled homologs in rheumatoid arthritis. Proc Natl Acad Sci USA 2000;97:2791-6.

34 Joutel A, Tournier-Lasserve E. Notch signalling pathway and human diseases. Semin Cell Dev Biol 1998;9:619-25.

$35 \mathrm{Li} \mathrm{L}, \mathrm{Krantz}$ ID, Deng Y, et al. Alagille syndrome is caused by mutations in human Jagged 1 , which encodes a ligand for Notch1. Nat Genet 1997;16:243-51.

36 Louis AA, Van Eyken P, Haber BA, et al. Hepatic jagged 1 expression studies. Hepatology 1999;30:1269-75.

37 Washburn T, Schweighoffer E, Gridley T, et al. Notch activity influences the alphabeta versus gammadelta $\mathrm{T}$ cell lineage decision. Cell 1997;88:833-43.

38 Robey E, Chang D, Itano A, et al. An activated form of Notch influences the choice between CD4 and CD8 T cell lineages. Cell 1996;87:483-92.

39 Boutros M, Mlodzik M. Dishevelled: at the crossroads of divergent intracellular signaling pathways. Mech Dev 1999; 83:27-37.

40 Dierick H, Bejsovec A. Cellular mechanisms of wingless/ Wnt signal transduction. Curr Top Dev Biol 1999;43:15390.

41 Itoh K, Sokol SY. Graded amounts of Xenopus dishevelled specify discrete anteroposterior cell fates in prospective specify discrete anteroposterior cell fate
ectoderm. Mech Dev 1997;61:113-25.

42 Merino R, Macias D, Ganan Y, et al. Control of digit formation by activin signalling. Development 1999;126:2161-70.

43 Kogure K, Omata W, Kanzaki M, et al. A single intraportal administration of follistatin accelerates liver regeneration in partially hepatectomized rats. Gastroenterology 1995;108: 1136-42.

44 Kogure $\mathrm{K}$, Zhang YQ, Shibata $\mathrm{H}$, et al. Immediate onset of DNA synthesis in remnant rat liver after $90 \%$ hepatectomy by an administration of follistatin. F Hepatol 1998;29:97784.

45 Yasuda $\mathrm{H}$, Mine T, Shibata $\mathrm{H}$, et al. Activin A: an autocrine inhibitor of initiation of DNA synthesis in rat hepatocytes. f Clin Invest 1993;92:1491-6.

46 Kogure K, Zhang YQ, Maeshima A, et al. The role of activin and transforming growth factor-beta in the regulation of organ mass in the rat liver. Hepatology 2000;31:916-21.
47 Phillips DJ, de Kretser DM. Follistatin: a multifunctional regulatory protein. Front Neuroendocrinol 1998;19:287322 .

48 Russell CE, Hedger MP, Brauman JN, et al. Activin A reguates growth and acute phase proteins in the human liver cell line, HepG2. Mol Cell Endocrinol 1999;148:129-36.

49 Schwall RH, Robbins K, Jardieu P, et al. Activin induces cell death in hepatocytes in vivo and in vitro. Hepatology 1993; 18:347-56

50 Zhang YQ, Kanzaki M, Shibata H, et al. Regulation of the expression of follistatin in rat hepatocytes. Biochim Biophys Acta 1997;1354:204-10.

51 Berg PA, Klein R, Rocken M. Cytokines in primary biliary cirrhosis. Semin Liver Dis 1997:17:115-23.

52 Tjandra K, Sharkey KA, Swain MG. Progressive development of a Th1-type hepatic cytokine profile in rats with experimental cholangitis. Hepatology 2000;31:280-90.

53 Jones DE, Palmer JM, Yeaman SJ, et al. Breakdown of tolerance to pyruvate dehydrogenase complex in experimental autoimmune cholangitis: a mouse model of primary biliary cirrhosis. Hepatology 1999;30:65-70.

54 Friedman SL. Molecular regulation of hepatic fibrosis, an integrated cellular response to tissue injury. $f \mathrm{Biol}$ Chem 2000;275:2247-50.

55 Marra F, DeFranco R, Grappone C, et al. Increased expression of monocyte chemotactic protein-1 during active hepatic fibrogenesis: correlation with monocyte infiltration. Am f Pathol 1998;152:423-30.

56 Baer HU, Friess H, Abou-Shady M, et al. Transforming growth factor betas and their receptors in human liver cirrhosis. Eur F Gastroenterol Hepatol 1998;10:1031-9.

57 Santos RM, Norton P, Degli Esposti S, et al. TGF-beta isoforms in alcoholic liver disease. $\mathcal{F}$ Gastroenterol 1998;33: $383-9$.

58 Grotendorst GR. Connective tissue growth factor: a mediator of TGF-beta action on fibroblasts. Cytokine Growth Factor Rev 1997;8:171-9.

59 Biswas C, Zhang Y, DeCastro R, et al. The human tumor cell-derived collagenase stimulatory factor (EMMPRIN) is a member of the immunoglobulin superfamily. Cancer Res 1995;55:434-9.

60 DeCastro R, Zhang Y, Guo H, et al. Human keratinocytes express EMMPRIN, an extracellular matrix metalloproteinase inducer. F Invest Dermatol 1996;106:1260-5.

61 Guo H, Zucker S, Gordon MK, et al. Stimulation of matrix metalloproteinase production by recombinant extracellular matrix metalloproteinase inducer from transfected Chinese hamster ovary cells. f Biol Chem 1997;272:24-7.

$62 \mathrm{Lim}$ M, Martinez T, Jablons D, et al. Tumor-derived EMMPRIN (extracellular matrix metalloproteinase inp38. FEBS Lett 1998;441:88-92.

63 Hlavcák P, Sedláková O, Sedlák J, et al. Cell surface immunophenotype and gelatinase activity of the human breast carcinoma cell line (MCF-7/6) with functionally defective E-cadherin. Neoplasma 1999;46:12-16.

64 Harada K, Kono N, Tsuneyama K, et al. Cell-kinetic study of proliferating bile ductules in various hepatobiliary diseases. Liver 1998;18:277-84.

65 Wang EH, Zou S, Tjian R. TAFII250-dependent transcription of cyclin A is directed by ATF activator proteins. Genes Dev 1997;11:2658-69.

66 Wang EH, Tjian R. Promoter-selective transcriptional defect in cell cycle mutant ts 13 rescued by hTAFII 250 . Science 1994;263:811-14.

67 Kaplan DR, Miller FD. Signal transduction by the neurotrophin receptors. Curr Opin Cell Biol 1997;9:21321.

68 Airaksinen MS, Titievsky A, Saarma M. GDNF family neurotrophic factor signaling: four masters, one servant? $\mathrm{Mol}$ Cell Neurosci 1999;13:313-25.

69 van Weering DH, Bos JL. Signal transduction by the receptor tyrosine kinase Ret. Recent Results Cancer Res 1998;154: 271-81.

70 Takahashi M, Asai N, Iwashita T, et al. Mechanisms of development of multiple endocrine neoplasia type 2 and Hirschsprung's disease by ret mutations. Recent Results Cancer Res 1998:154:229-36.

71 Ehrhard PB, Erb P, Graumann U, et al. Expression of nerve growth factor and nerve growth factor receptor tyrosine kinase Trk in activated CD4-positive T-cell clones. Proc Natl Acad Sci USA 1993;90:10984-8.

72 Torcia M, Bracci-Laudiero L, Lucibello M, et al. Nerve growth factor is an autocrine survival factor for memory B lymphocytes. Cell 1996;85:345-56.

73 Braun A, Appel E, Baruch R, et al. Role of nerve growth factor in a mouse model of allergic airway inflammation and asthma. Eur f Immunol 1998;28:3240-51.

74 Levy MT, McCaughan GW, Abbott CA, et al. Fibroblast activation protein: a cell surface dipeptidyl peptidase and gelatinase expressed by stellate cells at the tissue remodelling interface in human cirrhosis. Hepatology 1999;29: 1768-78.

75 Niki T, Pekny M, Hellemans K, et al. Class VI intermediate filament protein nestin is induced during activation of rat hepatic stellate cells. Hepatology 1999;29:520-7.

76 Cassiman DM, Van Pelt JF, De Vos R, et al. Synaptophysin: a novel marker for human and rat hepatic stellate cells. $\mathrm{Am}$ 7 Pathol 1999;155:1831-9.

77 Messing A. Nestin in the liver-Lessons from the brain Hepatology 1999;29:602-3. 
78 McCaughan GW, Gorrell MD, Bishop GA, et al. Molecular pathogenesis of liver disease: an approach to hepatic inflammation, cirrhosis and liver transplant tolerance. Immunol Rev 2000;174:172-91.

79 Trim N, Morgan S, Evans M, et al. Hepatic stellate cells express the low affinity nerve growth factor receptor $\mathrm{p} 75$ and undergo apoptosis in response to nerve growth factor stimulation. Am f Pathol 2000;156:1235-43.
80 Shim C, Zhang W, Rhee CH, et al. Profiling of differentially expressed genes in human primary cervical cancer bycomplementary DNA expression array. Clin Cancer Res 1998; $3045-50$

81 Sehgal A, Boynton AL, Young RF, et al. Application of the differential hybridization of Atlas Human expression arrays technique in the identification of differentially expressed genes in human glioblastoma multiforme tumor tissue. $\mathcal{F}$ Surg Oncol 1998;67:234-41.

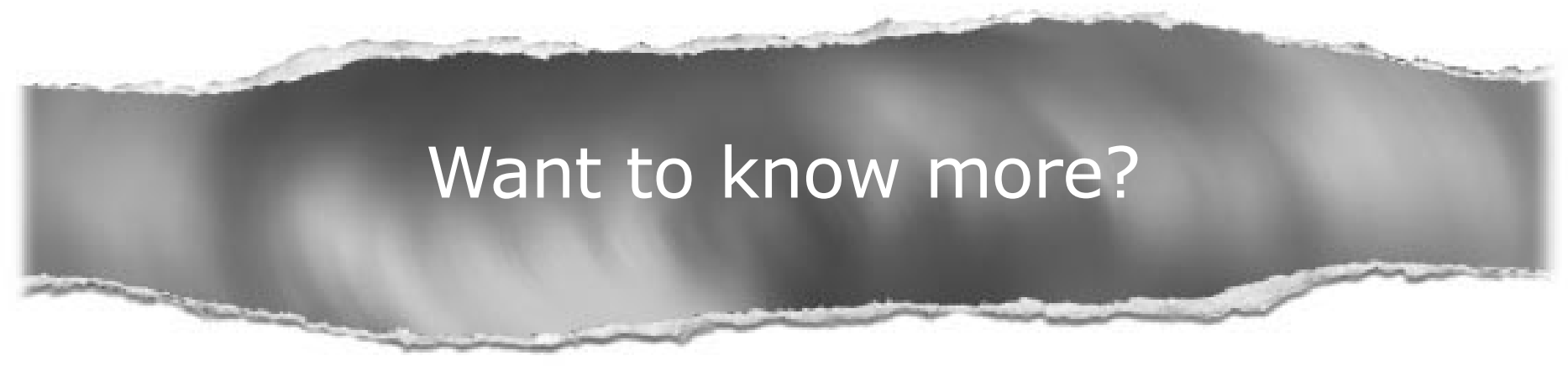

\section{Data supplements}

Limited space in printed journals means that interesting data and other material are often edited out of articles; however, limitless cyberspace means that we can include this information online.

Look out for additional tables, references, illustrations.

www.gutjnl.com 